\title{
Improving The Oral Absorption Of Nintedanib By A Self-Microemulsion Drug Delivery System: Preparation And In Vitro/In Vivo Evaluation
}

This article was published in the following Dove Press journal: International Journal of Nanomedicine

\author{
Hongfei Liu' \\ Jiaao $\mathrm{Mei}^{\prime}$ \\ Ying $X u^{\prime}$ \\ Lei Tang' \\ Daquan Chen $\mathbb{D}^{2}$ \\ Yating Zhu' \\ Shuguang Huang' \\ Thomas J Webster ${ }^{3}$ \\ Hui Ding ${ }^{4}$ \\ 'College of Pharmacy, Jiangsu University, \\ Zhenjiang 212013, People's Republic of \\ China; ${ }^{2}$ School of Pharmacy, Yantai \\ University, Yantai 264005, People's \\ Republic of China; ${ }^{3}$ Department of \\ Chemical Engineering, Northeastern \\ University, Boston, MA 02II5, USA; \\ ${ }^{4}$ Department of Respiratory and Critical \\ Care Medicine, The Affiliated Yixing \\ Hospital of Jiangsu University, Yixing, \\ Jiangsu 214200, People's Republic of \\ China
}

Correspondence: Hui Ding

Department of Respiratory and Critica

Care Medicine, The Affiliated Yixing

Hospital Of Jiangsu University, Yixing,

Jiangsu 214200, People's Republic of

China

Tel +860I370656506

EmaildhI350519@163.com

Thomas J Webster

Department Of Chemical Engineering,

Northeastern University, Boston, MA

02115 , USA,

$\mathrm{Tel}+16173736585$

Email th.webster@neu.edu
Objective: Nintedanib (NDNB) is a triple receptor tyrosine kinase inhibitor with poor solubility in neutral conditions and low bioavailability. A self-microemulsifying drug delivery system (SMEDDS) of NDNB was developed to improve drug solubility in physical conditions and absorption in vivo.

Methods: The NDNB-SMEDDS formulation was optimized via pseudo-ternary phase diagrams. The physicochemical properties of NDNB-SMEDDS, viz., morphological observation, droplet size, stability, compatibility and in vitro release were investigated. The permeability of NDNB-SMEDDS was detected using both a Caco-2 cell monolayer in vitro and an intestinal perfusion study in vivo. Furthermore, the pharmacokinetic characteristics of NDNB-SMEDDS were evaluated.

Results: The optimal formulation was composed of MCT as an oil phase, RH 40 as a surfactant and ethylene glycol as a co-surfactant. The average droplet size of the microemulsion was about $23 \mathrm{~nm}$ with good stability within 30 days. The formulation did not exhibit any obvious cytotoxic effect on Caco-2 cells. Permeability of nintedanib in a Caco-2 cell monolayer was enhanced by 2.8 -fold upon incorporation in SMEDDS compared with the drug solution. The intestinal perfusion study demonstrated that the $P_{\text {app }}$ of NDNB-SMEDDS increased by 3.0 -fold in the entire intestine and 3.2-fold in the colon in comparison with the drug solution. The pharmacokinetics study showed that the AUC of the NDNB-SMEDDS increased significantly.

Conclusion: This study showed that the self-microemulsion formulations could improve the absorption of nintedanib, and can thus serve as a promising carrier for the oral delivery of nintedanib.

Keywords: nintedanib, self-microemulsion drug delivery system, solubility, permeability, Caco-2 cell, intestinal perfusion, pharmacokinetics, bioavailability

\section{Introduction}

Idiopathic pulmonary disease (IPF) is a chronic, progressive and irreversible fatal fibrotic disease of the lung. The median survival of patients with IPF is only 2.5 to 3.5 years, ${ }^{1}$ with only $20 \%$ to $30 \%$ of subjects being alive 5 years after diagnosis. ${ }^{2}$ Nintedanib (NDNB) is a triple inhibitor of receptor tyrosine kinases, namely fibroblast growth factor receptor (FGFR), vascular endothelial growth factor receptor (VEGFR) and platelet-derived growth factor receptor (PDGFR). ${ }^{3,4}$ As reported elsewhere, nintedanib could be used to treat $\mathrm{IPF}^{5,6}$ and a variety of cancers, such as small cell lung cancer, ${ }^{7}$ renal cancer, ${ }^{8}$ colorectal cancer, ${ }^{9}$ ovarian cancer and prostate 
cancer. ${ }^{4}$ Historically, nintedanib received its first global approval in the US in October 2014 for IPF treatment and obtained a positive opinion from the European Medicines Agency's Committee for Medicinal Products for Human Use in the treatment of IPF. ${ }^{10}$ Indeed, Ofev ${ }^{\circledR}$ is an orally available product of nintedanib soft capsule developed by Boehringer Ingelheim for the treatment of IPF and cancer. However, according to the literature, the bioavailability of the nintedanib orally product is slightly below $5 \%,{ }^{11}$ probably due to its poor solubility in the relatively neutral intestinal environment. Generally, the poor absorption and low bioavailability greatly affect the pharmacodynamics effect of nintedanib in vivo. Until now, only a few studies have focused on improving the oral bioavailability of nintedanib.

Self-microemulsifying drug delivery systems (SMEDDS) which have high solubilization potential and thermodynamic stability are considered ideal alternative oral drug delivery carriers for drugs with poor solubility in water. Notably, SMEDDS are comprised of an oil phase, emulsifier and co-emulsifier. In terms of the main feature, SMEDDS can automatically form a water-containing $(\mathrm{O} / \mathrm{W})$ type of microemulsion under physiological conditions, such as body temperature and gastrointestinal peristalsis. ${ }^{12}$ Functionally, SMEDDS can improve the solubility and permeability of drugs, as well as increase the absorption rate of drugs to increase bioavailability and drug stability. ${ }^{13-15}$ Consequently, SMEDDS technology has been applied to a series of drugs, such as dipyridamole,${ }^{16}$ nifedipine, ${ }^{17}$ ibuprofen, ${ }^{18}$ loratadine ${ }^{19}$ and docetaxel ${ }^{20}$ with enhanced absorption being demonstrated.

With regard to an orally delivered product, besides solubility, permeability is also widely acknowledged to be important for drug absorption in gastrointestinal. ${ }^{21}$ Solubility and permeability are two important parameters which are used in the Biopharmaceuticals Classification System (BCS) to predict the absorption of a drug. Caco-2 cells which are derived from human colon carcinoma cells are widely used as an in vitro model of human small intestinal mucosa to predict the absorption of orally administered drugs, owing to their morphological and functional similarity with human enterocytes. ${ }^{22}$ However, to the best of the author's knowledge, there is a paucity of available literature on the permeability properties of nintedanib conducted using the Caco-2 cell model.

In our previous study, we used solid dispersion technology to enhance the bioavailability of nintedanib; the relevant bioavailability of NDNB-SDSC was $162 \%$ compared to the nintedanib soft capsule. ${ }^{23}$ So far, SMEDDS, which is a promising technology for improving both solubility and permeability, has not been explored for the oral delivery of nintedanib. Therefore, we conducted this study to develop SMEDDS loaded with nintedanib to further enhance the absorption and bioavailability of the drug. The optimized formulation of SMEDDS was determined and the physicochemical properties of SMEDDS were evaluated. In addition, we investigated the transport and permeability properties of nintedanib using a Caco-2 cell model and intestinal perfusion experiment, which could provide the guidance for the design of an oral preparation with high nintedanib bioavailability.

\section{Materials And Methods Materials}

Nintedanib ( $\geq 99 \%)$ was purchased from Hubei Dibai Chemical Co., Ltd (People's Republic of China). Nintedanib soft capsule $\left(\mathrm{Ofev}^{\circledR}\right)$ was bought from Boehringer Ingelheim (Ingelheim, Germany). Medium chain triglycerides (MCT) were provided by Beijing Fengli Precision Co., Ltd (People's Republic of China). Cremophor RH 40 and Cremophor EL were gifts from BASF (Germany) while all other chemicals, reagents and solvents were obtained from Sinopharm Group Chemical Reagent Co., Ltd (People's Republic of China).

\section{Quantification Of Nintedanib}

A high-performance liquid chromatography (HPLC) system equipped with an Agilent G1315D Pump and Agilent G1311 detector (Agilent, USA) was adopted in this study. The unitary C18 column $(250 \times 4.6 \mathrm{~mm}, 5 \mu \mathrm{m})$ was used. The mobile phase was composed of methanol-water (containing $0.05 \%$ triethylamine, $\mathrm{pH}$ adjusted to 5.0 with phosphoric acid) at the ratio of 90:10. The column temperature was $30^{\circ} \mathrm{C}$ and the detection wavelength was set at $391 \mathrm{~nm}$. Standard curves were used for each experiment $\left(\mathrm{R}^{2}>0.9995\right)$ and the limit of quantification was $70 \mathrm{ng} \mathrm{mL}^{-1}$.

\section{Solubility Of Nintedanib}

The solubilities of nintedanib in different $\mathrm{pH}$ conditions, viz., pH 6.8 PBS (with, or without $0.5 \%$ Tween 80 ) and $\mathrm{pH}$ 7.4 PBS (with or without $0.5 \%$ Tween 80 ) were determined. In brief, excessive nintedanib was added into $5 \mathrm{~mL}$ of media and then the mixtures were mixed in a constant temperature oscillator (SHZ-88A, ZhongDa, Jintan, People's Republic of China) at $100 \mathrm{rpm}$ at $25^{\circ} \mathrm{C}$ for $72 \mathrm{hrs}$. After that, the undissolved drug was separated by centrifugation at 12,000 rpm for 10 mins. The drug content in the clear supernatant 
was determined via an HPLC system after suitable dilution with methanol.

\section{Determination Of LogP Of Nintedanib}

Water phase and octanol were saturated by each other before use. After that, nintedanib was added into an octanol phase, and then the water phase was added to the mixture at a volume ratio of 1:1 (water phase to octanol phase). The mixtures were placed on a thermomixer (300 $\mathrm{rpm}, 37^{\circ} \mathrm{C}$ ) for $24 \mathrm{hrs}$ followed by phase separation via centrifugation ( $5 \mathrm{mins}, 12,000 \mathrm{rpm}$ ). The concentration of nintedanib in water and octanol phase was determined by HPLC after suitable dilution with methanol. The $\log P$ of nintedanib was calculated by the following equation:

$$
\log P=\log \left(C_{0} / C_{w}\right)
$$

$C_{o}$ was the concentration of nintedanib in octanol; $C_{w}$ was the concentration of nintedanib in water phase.

\section{Construction Of Pseudo-Ternary Phase Diagrams And Preparation Of NDNB- SMEDDS}

NDNB-SMEDDS was prepared by constructing pseudoternary phase diagrams, which were applied to confirm the optimal formula. Briefly, MCT was the oily phase with Cremophor RH40 employed as the surfactant. Notably, PEG400, ethylene glycol and glycerol were evaluated as co-surfactants at a 2:1 wt. ratio of Cremophor RH40. Mixtures of MCT, Cremophor RH40 and co-surfactants were prepared at weight ratios from 9:1 to 1:9. The mixtures were titrated into water slowly while monitoring the phase behavior of the pseudo-ternary system. The formation of the microemulsion (ME) was identified via visual observation with a single phase transparent fluid system considered as a microemulsion. Likewise, turbid dispersions were characterized as coarse emulsion. Based on these observations, the $\mathrm{ME}$ region was marked in the ternary phase diagram.

After the co-surfactant was confirmed, the Km (surfactant to co-surfactant) was also investigated by varying the ratio of surfactant to co-surfactant $(3: 1,2: 1,1: 2)$.

\section{Characterization Of NDNB-SMEDDS Determination Of Self-Emulsifying Rate And Droplet Size}

The NBND-SMEDDS (0.5 g) was rapidly injected into $50 \mathrm{~mL}$ of distilled water by gentle stirring at room temperature. Emulsifying time (T) was recorded, that is from injection to the self-microemulsion was clear and slightly bluish in appearance. The droplet size and zeta potentials of NDNB-SMEDDS were measured with a Mastersizer 3000 (Malvern, England) after a 50-fold dilution with distilled water at room temperature.

\section{Appearance And Morphological Characterization}

The morphology of the NDNB-SMEDDS formulation was observed by a transmission electron microscope (TEM, Tecnai 12, Philips, Holland). The optimal NDNB-SMEDDS was diluted 50 times with distilled water at $37^{\circ} \mathrm{C}$. A drop of filtrate was deposited on a film-coated copper grid and negatively stained with $2 \%$ phosphotungstic acid for $30 \mathrm{~s}$. After drying at room temperature, the morphology of the NDNB-SMEDDS was observed by TEM.

\section{Stability Of NDNB-SMEDDS}

The NDNB-SMEDDS samples were tightly sealed and placed in an environment of $4^{\circ} \mathrm{C}$ and $30^{\circ} \mathrm{C}$ for 30 days, accordingly, and the stability of NDNB-SMEDDS was evaluated. The droplet size and the appearance were assessed at $1 \mathrm{~d}, 15 \mathrm{~d}$ and $30 \mathrm{~d}$.

\section{In Vitro Release}

In vitro release of NDNB-SMEDDS was determined by the dialysis method. ${ }^{24}$ Free nintedanib and NDNB-SMEDDS were accordingly added into dialysis bags $(\mathrm{Mn}=14000 \mathrm{Da}$, mlbio, Shanghai, People's Republic of China). The dialysis bags were placed into different release media $(900 \mathrm{~mL})$, which included ultra-pure water, pH6.8 PBS (including $0.5 \%$ Tween 80 ) and pH7.4 PBS (including 0.5\% Tween $80)$ under the rotation rate of $75 \mathrm{rpm}$ at $37^{\circ} \mathrm{C}$. A sample $(5 \mathrm{~mL})$ was withdrawn at predetermined time points $(0.5 \mathrm{hr}$, $0.75 \mathrm{hr}, 1 \mathrm{hr}, 1.5 \mathrm{hrs}, 2 \mathrm{hrs}, 3 \mathrm{hrs}, 4 \mathrm{hrs}, 5 \mathrm{hrs}, 6 \mathrm{hrs}, 8 \mathrm{hrs}$ and $12 \mathrm{hrs}$ ) while the same volume of fresh buffer was added. The concentration of nintedanib was analyzed with the HPLC method, while the accumulative release percentage was calculated. All the experiments were performed in triplicate.

\section{Cytotoxicity Study}

The cytotoxicity of NDNB-SMEDDS to Caco-2 cells (product code ml055590, mlbio, Shanghai, People's Republic of China) was evaluated via the MTT assay method. ${ }^{25}$ Briefly, Caco-2 cells were cultivated in Dulbecco's Modified Eagle's Medium (DMEM; Gibco, Carlsbad, CA, USA) supplemented with fetal bovine serum (FBS, 
$10 \% \mathrm{v} / \mathrm{v} ;$ Gibco) containing penicillin/streptomycin ( $1 \%$, Gibco), in a $\mathrm{CO}_{2}(5 \%)$ and relatively humid (95\%) incubator (Forma 3111, Thermo, USA) at $37^{\circ} \mathrm{C}$. Cells were seeded in 96-well cell plates at a concentration of $1 \times 10^{5}$ cells/well and pre-incubated for 24 hrs. Subsequently, medium was replaced with serum-free medium comprised of different concentrations of NDNB-SMEDDS or blank SMEDDS (equal to the same amount of the drug-loaded microemulsion). Cells without treatment were used as the control. After $24 \mathrm{hrs,} \mathrm{cell} \mathrm{viability} \mathrm{was} \mathrm{determined} \mathrm{with} \mathrm{an}$ MTT assay. The average optical density (OD) of cells was measured with a microplate reader (800TS, Bio-Tek, USA) at $570 \mathrm{~nm}$. The cell viability was calculated.

\section{Transport Of NDNB-SMEDDS Through The Caco-2 Cell Monolayer}

Caco-2 cells were seeded onto the apical side of collagencoated Transwell-COL inserts in a 12-well Transwell culture plate (Corning Costar Co.) at $1 \times 10^{5}$ cells/well. DMEM was added to the apical $(0.5 \mathrm{~mL})$ and basolateral $(1.5 \mathrm{~mL})$ side. Next, the medium was replaced every other day for the first week and daily from 8th to 21st days, until the transepithelial electrical resistance (TEER) increased to about $600 \Omega / \mathrm{cm}^{2}$, which was measured with a voltohmmeter (RE1600, DongGong, Peking, People's Republic of China).

Permeability studies were performed in both side directions, from apical to basolateral $(A$ to $B)$ and basolateral to apical ( $B$ to $A$ ). After the cell monolayer was washed and equilibrated with pre-warmed HBSS medium (pH 7.4), the nintedanib solution or NDNB-SMEDDS was added to the apical side $(A, 0.5 \mathrm{~mL})$ for the $\mathrm{A}$ to $\mathrm{B}$ direction or to the basolateral side $(B, 1.5 \mathrm{~mL})$ for the $B$ to $A$ direction. $A$ medium $(0.2 \mathrm{~mL})$ was taken from the acceptor compartment at $2 \mathrm{hrs}$ and immediately preserved below $20^{\circ} \mathrm{C}$ for HPLC analysis. The entire experiments were performed in triplicate. The apparent permeability coefficient $\left(P_{\text {app }}\right)$ and efflux ratio were calculated according to the following equation:

$$
P_{\text {app }}=\Delta Q /\left(\Delta \mathrm{t} \cdot A \cdot C_{0}\right) \mathrm{cm} \cdot \mathrm{s}^{-1}
$$

where $P_{\text {app }}$ is the apparent permeability coefficient $\left(\mathrm{cm} \cdot \mathrm{s}^{-1}\right)$, $\mathrm{d} Q / \mathrm{d} t$ is the steady-state permeability rate, $A$ is the diffusion area of monolayer membrane $\left(\mathrm{cm}^{2}\right)$, and $C_{\mathrm{o}}$ is the initial concentration of nintedanib in the apical (for $A$ to $B$ transport) or basolateral (for $B$ to $A$ transport) side.

$$
\text { Efflux ratio }=P_{\text {app }}(B \text { to } A) / P_{\text {app }}(A \text { to } B)
$$

while the efflux ratio was expressed as the quotient of $P_{\text {app }}$ ( $B$ to $A$ ) to $P_{\text {app }}(A$ to $B)$.

\section{Doluisio's (Closed-Loop) Rat Intestinal Perfusion}

All the experimental protocols were approved by the Jiangsu University Animal Ethics and Experimentation Committee and followed the principles of laboratory and animal care of the university (UJS-LAER-AP-2018030809).

Male Sprague-Dawley rats (180-220 g) were obtained from the Jiangsu University Animal Center (Zhenjiang, People's Republic of China). The absorption rate coefficients of nintedanib and its SMEDDS were determined in four intestinal segments (the duodenum, jejunum, ileum and colon) using the in situ "closed-loop" perfusion method based on the Doluisio's Technique ${ }^{26,27}$ with minor modification. Briefly, rats were fasted for $4 \mathrm{hrs}$ (free access to water) and randomly divided into 2 groups (nintedanib solution and NDNB-SMEDDS groups). After anesthesia by using sodium pentobarbital $\left(40 \mathrm{mg} \cdot \mathrm{kg}^{-1}\right.$ ), the rat was fixed on a heated surface maintained at $37^{\circ} \mathrm{C}$ and a midline abdominal incision was made. ${ }^{28}$ According to the position shown in Table 1, four individual $10 \mathrm{~cm}$ of intestinal segments (the duodenum, jejunum, ileum and colon) or entire small intestine (from the duodenum to ileum) were cut and cannulated at both ends. The bile duct was tied up to avoid drug enterohepatic circulation and the presence of bile salts in the lumen. In order to remove the intestinal contents, the four intestinal segments were flushed with a $37^{\circ} \mathrm{C}$ physiological solution. Then, the intestinal segments were connected with three-way stopcock valves. Throughout the experiment, the abdomen was covered with a cotton wool pad to avoid peritoneal liquid evaporation and heat loss. The nintedanib solution and NDNB-SMEDDS were diluted with a K-R solution to 20 $\mu \mathrm{g} \cdot \mathrm{mL}^{-1}$, which contained phenol red which was then introduced into each segment and circulated at 2.5 $\mathrm{mL} \cdot \mathrm{min}^{-1}$ and $37^{\circ} \mathrm{C}$. Samples were taken at $0.5,1,1.5$, 2, 2.5 and $3 \mathrm{hrs}$, while the same volume of blank medium was added. Next, samples were centrifuged at 10,000 $\mathrm{r} \cdot \mathrm{min}^{-1}$ for $10 \mathrm{mins}$, and the drug concentration was determined by an HPLC assay.

Table I The Specific Location Of The Intestinal Segments

\begin{tabular}{|l|l|}
\hline Intestine & Site \\
\hline Duodenum & Starting $2 \mathrm{~cm}$ distal to stomach pylorus \\
Jejunum & Starting $4 \mathrm{~cm}$ after duodenal exit \\
Ileum & Starting $12 \mathrm{~cm}$ distal to cecum point \\
Colon & Starting $2 \mathrm{~cm}$ after cecum point \\
\hline
\end{tabular}




$$
\operatorname{LnX}=\operatorname{Ln} X_{0}-K_{a} t
$$

$X_{0}$ was the drug concentration in the intestinal circulating fluid at $0 \mathrm{hr}, \operatorname{Ln} X$ is the $\ln$ value of the remaining nintedanib dose in the enteric circulation fluid at each time point.

According to Equation 4, linear regression was carried through on $\operatorname{Ln} X$ and $t$, the slope of the line was the absorption rate coefficient $\left(K_{a}\right)$.

$K_{a}$ was transformed into a permeability value $\left(P_{\text {app }}\right)$ with the following equation:

$$
P_{\text {app }}=K_{a} \cdot R / 2
$$

where $R$ is the effective radius of the intestinal segment, while $R$ was calculated from the area/volume relationship considering a $2 \mathrm{~mL}$ and $5 \mathrm{~mL}$ volume of each intestinal segments and colon, respectively.

The predicted oral fraction absorbed $\left(F_{\mathrm{abs}}\right)$ obtained with the perfusion approach was calculated from the following equation:

$$
F_{\text {abs }}=1-\mathrm{e}\left(-P_{\text {app }} \cdot 2 / R \cdot T\right)
$$

$R$ represents the effective radius of the small intestine (fixed at a value of $0.1630 \mathrm{~cm}$ ) or colon (fixed at a value of $0.3718 \mathrm{~cm}$ ), and $T$ is the effective absorption time.

\section{In Vivo Pharmacokinetic Studies}

Male Sprague-Dawley rats (180-220 g) were fasted for 12 hrs before the experiment, but allowed unrestricted access to water. The rats were divided randomly into two groups $(n=5)$ and orally administered with the contents of the nintedanib soft capsule or NDNB-SMEDDS (with a nintedanib dose of $\left.50 \mathrm{mg} \cdot \mathrm{kg}^{-1}\right)$, respectively. Aliquots $(0.2$ $\mathrm{mL}$ ) of blood samples were harvested at $0.5,1.0,1.5,2.0$, 3.0, 4.0, 6.0, 8.0 and 12-hr post-administration. Blood samples were centrifuged at $10,000 \mathrm{r} \cdot \mathrm{min}^{-1}$ for $5 \mathrm{mins}$, and plasma was collected. A quantity of $100 \mu \mathrm{L}$ of plasma was withdrawn and added with $10 \mu \mathrm{L}$ of the internal standard solution (32 $\mu \mathrm{g} \cdot \mathrm{mL}-1$ carbamazepine solution) and $400 \mu \mathrm{L}$ methanol, then the mixture was shaken for 2 mins and centrifuged at $10,000 \mathrm{r} \cdot \mathrm{min}^{-1}$ for $5 \mathrm{mins}$. The supernatant was dried with nitrogen at $40^{\circ} \mathrm{C}$. Then, an appropriate volume of methanol was added and shaken for $1 \mathrm{~min}$ and the methanol solution was centrifuged at $10,000 \mathrm{r} \cdot \mathrm{min}^{-1}$ for $5 \mathrm{mins}$. The supernatant was analyzed with HPLC. The pharmacokinetic parameters of the two dosage forms were attained using a software program (DAS2.0). Relative bioavailability was evaluated according to Equation 7:

$$
F_{r}=\frac{A U C_{T}}{A U C_{R}} \times 100 \%
$$

$\mathrm{AUC}_{\mathrm{T}}$ is the $\mathrm{AUC}$ of the NDNB-SMEDDS, and $\mathrm{AUC}_{\mathrm{R}}$ is the AUC of the nintedanib soft capsule.

\section{Statistical Data Analysis}

All the experiments were performed at least three times and the data are expressed as the mean \pm standard deviation (SD). One-way ANOVA followed by a post hoc Student-Newman-Keuls test (SPSS 13; SPSS Int., Chicago, IL, USA) was applied to compare the experimental groups and the corresponding controls. Significant differences between or among groups were acceptable at $* \mathrm{P}<0.05, * * \mathrm{P}<0.01$ and $* * * \mathrm{P}<0.001$.

\section{Results And Discussion \\ Solubility And LogP Of Nintedanib}

The solubility of nintedanib in different $\mathrm{pH}$ conditions, viz., pH6.8 PBS (with, or without $0.5 \%$ Tween 80 ) and pH7.4 PBS (with or without $0.5 \%$ Tween 80 ) was detected to predict its solubility under physiological conditions and a sink condition for the in vitro release study. As shown in Table 2, the solubility of nintedanib in the $\mathrm{pH} 6.8$ and $\mathrm{pH} 7.4$ condition was very low, which lead to its poor absorption in the intestine. In order to increase the solubility at physiological $\mathrm{pH}, 0.5 \%$ Tween 80 was added to $\mathrm{pH} 6.8$ and $\mathrm{pH} 7.4 \mathrm{PBS}$, and the solubility of nintedanib enhanced from 11.98 to 441.67 and 5.13 to $132.42 \mu \mathrm{g}$. $\mathrm{mL}^{-1}$ respectively, which could satisfy the sink condition.

As displayed in Table 3, the oil/water partition coefficient $(\log P)$ of nintedanib varied with water phase. The $\log P$ of nintedanib in both $\mathrm{pH} 6.8$ and $\mathrm{pH} 7.4$ water phases were more than 2 , indicating that nintedanib was more

Table 2 Solubility Of Nintedanib In Different Medium ( $X \pm S D, n=3$ )

\begin{tabular}{|l|l|l|l|l|}
\hline Solvent & $\begin{array}{l}\text { pH 6.8 } \\
\text { PBS }\end{array}$ & $\begin{array}{l}\text { pH 6.8 PBS } \\
(\mathbf{0 . 5 \%} \\
\text { Tween 80) }\end{array}$ & $\begin{array}{l}\text { pH 7.4 } \\
\text { PBS }\end{array}$ & $\begin{array}{l}\text { pH 7.4 PBS } \\
\mathbf{( 0 . 5 \%} \\
\text { Tween 80) }\end{array}$ \\
\hline $\begin{array}{l}\text { Solubility } \\
\left(\mu \mathrm{gLL}^{-1}\right)\end{array}$ & $11.98 \pm 1.12$ & $441.67 \pm 10.25$ & $5.13 \pm 1.23$ & $132.42 \pm 8.87$ \\
\hline
\end{tabular}

Table 3 Oil/Water Partition Coefficient Of Nintedanib In Different Medium ( $X \pm S D, n=3$ )

\begin{tabular}{|l|l|l|l|l|}
\hline Solvent & $\begin{array}{l}\text { pH 6.8 } \\
\text { PBS }\end{array}$ & $\begin{array}{l}\text { pH 6.8 PBS } \\
(\mathbf{0 . 5 \%} \text { Tween } \\
\mathbf{8 0})\end{array}$ & $\begin{array}{l}\text { pH 7.4 } \\
\text { PBS }\end{array}$ & $\begin{array}{l}\text { pH 7.4 PBS } \\
\mathbf{( 0 . 5 \%} \text { Tween } \\
\mathbf{8 0})\end{array}$ \\
\hline $\log P$ & $2.40 \pm 0.15$ & $1.68 \pm 0.12$ & $2.85 \pm 0.24$ & $2.39 \pm 0.17$ \\
\hline
\end{tabular}


lipophilic than being hydrophilic. Even when the solubilizer Tween 80 was used in the water phase, the solubility of nintedanib in the oil phase was still higher than that in the water phase. As reported in the literature, SMEDDS approaches are potentially useful for drugs with poor water-solubility and intermediate partition coefficients $(2<\log P<4) .{ }^{29}$ Properly designed SMEDDS formulations may provide an opportunity to improve the intestinal absorption of nintedanib which has poor solubility in physiological conditions.

\section{Pseudo-Ternary Phase Diagram Study}

Based on the preliminary solubility and compatibility experiments, MCT was finally selected as an oil phase. The hydrophilic lipophilic balance (HLB) value is an important criterion for the selection of surfactants with the value usually above 10. Cremophor EL35 (HLB 13.5) and Cremophor RH 40 (HLB 14-16) are non-ionic, biocompatible surfactants approved for oral administration. In preliminary studies, Cremophor EL35 (HLB 13.5) and Cremophor RH 40 along with three co-surfactants were examined. Cremophor RH 40 exhibited a better emulsifying effect and was selected as the surfactant. Co-surfactants can enhance drug solubility within the formulation, and more importantly, could reduce the interfacial tension and increase the stability of the emulsion, which are most crucial for the emulsion system. In this study, ethylene glycol, PEG400 and glycerol were assessed as the co-surfactants. The pseudo-ternary phase diagram is well documented in the literature and has extensively been reported for the selection of the components of the microemulsions. The black areas of phase diagrams indicate the ME regions, whereas the white area represents the turbid region. As shown in Figure 1, the microemulsion area of diagram B with ethylene glycol as a co-surfactant was larger than diagram A (PEG400) and diagram C (glycerol). Based on this finding, ethylene glycol was selected as a co-surfactant.

The Km was confirmed by comparing the microemulsion area of ternary phase diagrams constructed with different ratios of surfactants to co-surfactants. As shown in Figure 1A-E, comparing with diagram $\mathrm{d}$ and $\mathrm{e}$, the area of diagram $\mathrm{b}$ was wider, so $\mathrm{Km}$ was confirmed as 2:1.

\section{Characterization Of NDNB-SMEDDS}

It was observed that NDNB-SMEDDS dispersed in water rapidly with the micro-emulsion being clear and slightly bluish in appearance at a recorded emulsifying time of about $47.2 \pm 0.6$ s. As shown in Figure 2, the appearance of NDNB-SMEDDS was a clear yellow transparent liquid (Figure 2A). The average droplet size was about $23 \mathrm{~nm}$ (Figure 2B), which was consistent with that of the morphological characterization (Figure 2C). The index of

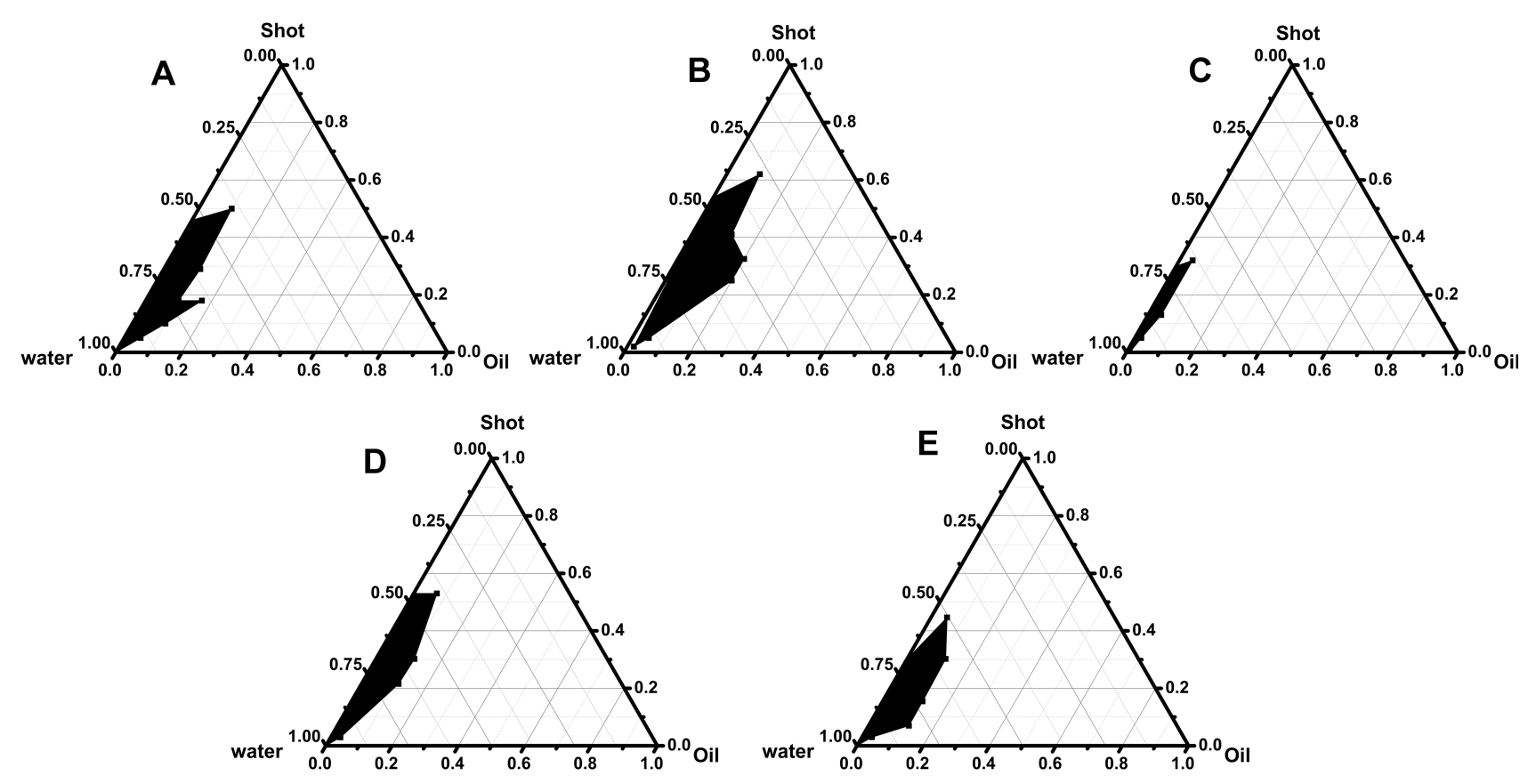

Figure I Pseudo-ternary phase diagrams composed of Cremophor RH 40 and (A) PEG400 (B) ethylene glycol, and (C) Glycerol as the surfactant and co-surfactant (I:I, w/w), respectively; Cremophor RH 40 and ethylene glycol as the surfactant and co-surfactant, respectively, with a ratio of (D) 3:I and (E) I:2, while MCTwas used as the oil phase. The black area represents the o/w microemulsion existence range. 


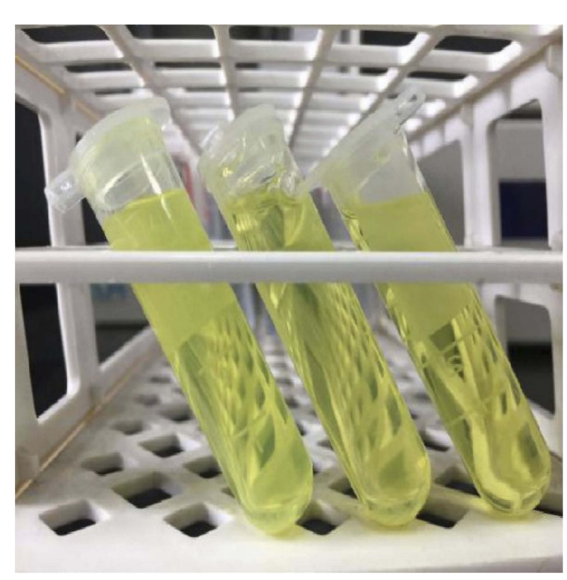

A

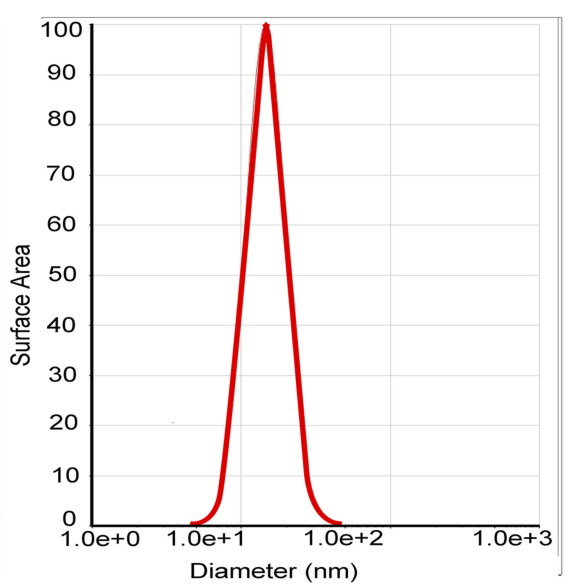

B

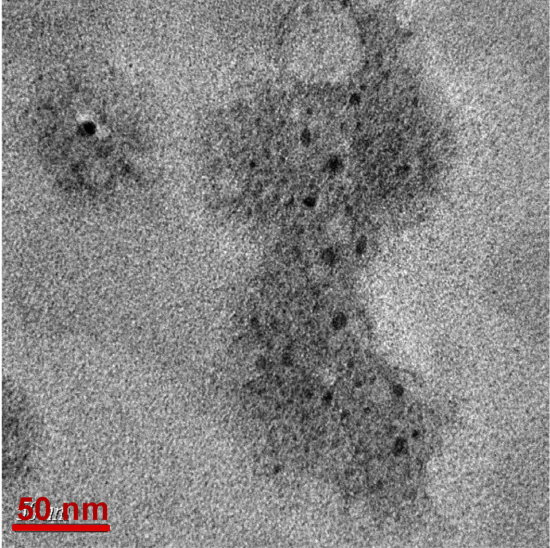

C

Figure 2 (A) Appearance of NDNB-SMEDDS. (B) Droplet size distribution of NDNB-SMEDDS. (C) Morphology of NDNB-SMEDDS.

polydispersity (PDI) was 0.201 , which indicated the uniformity of the droplet size within the formulation. The zeta potential was about $-19.5 \pm 2.3 \mathrm{mV}$. A previous report indicated that the smaller size of the microemulsion droplet was beneficial for increasing the in vivo absorption of the drug, while a lower zeta potential value could increase the stability of the self-microemulsion. ${ }^{30}$

\section{Stability Studies}

As shown in Table 4 , after 30 days stored at $4{ }^{\circ} \mathrm{C}$ and $30^{\circ} \mathrm{C}$, NDNB-SMEDDS showed no significant change in appearance and particle size. It was still a pale yellow transparent liquid without turbidity and delamination. The results inferred that the prepared NDNB-SMEDDS had a good stability within 30 days.

\section{Release Studies}

In order to satisfy the sink condition, ultra-pure water, pH6.8 and pH7.4 PBS containing 0.5\% Tween 80 was

Table 4 Temperature Effect On The Stability Of Optimized NDNB-SMEDDS $(X \pm S D, N=3)$

\begin{tabular}{|l|l|l|l|}
\hline $\begin{array}{l}\text { Time } \\
\text { (Days) }\end{array}$ & $\begin{array}{l}\text { Temperature } \\
\left({ }^{\circ} \mathbf{C}\right)\end{array}$ & Appearance & $\begin{array}{l}\text { Particle Size } \\
(\mathbf{n m})\end{array}$ \\
\hline $\mathrm{I}$ & 4 & Uniform & $23.3 \pm 0.2$ \\
& 30 & Uniform & $19.9 \pm 0.8$ \\
\hline 15 & 4 & Uniform & $23.8 \pm 0.9$ \\
& 30 & Uniform & $22.9 \pm 0.5$ \\
\hline 30 & 4 & Uniform & $22.5 \pm 0.4$ \\
& 30 & Uniform & $24.0 \pm 0.3$ \\
\hline
\end{tabular}

used for in vitro release experiments (as shown in Figure $3 \mathrm{~A}-\mathrm{C}$ ). The cumulative release rates of the nintedanib solution for $12 \mathrm{hrs}$ were, respectively, 54.01\%, $40.64 \%$ and $9.10 \%$ in the dissolution media, viz., ultrapure water, pH6.8 PBS (0.5\% Tween 80$)$ and $\mathrm{pH} 7.4$ PBS ( $0.5 \%$ Tween 80$)$. The cumulative release rates of NDNBSMEDDS in the corresponding dissolution media were $75.02 \%, 65.03 \%$ and $57.90 \%$, respectively. It was indicated that SMEDDS could significantly increase the cumulative release of nintedanib in the various dissolution media, especially in the simulated $\mathrm{pH} 7.4$ medium. Indeed, the cumulative release of nintedanib from SMEDDS was enhanced by about sixfold compared with that of the free drug at $12 \mathrm{hrs}$. Therefore, it could be speculated that the release of nintedanib in SMEDDS in the intestinal tract might be increased, which may enhance the absorption and bioavailability of nintedanib.

\section{Cytotoxicity Studies Of NDNB-SMEDDS}

An MTT assay was performed to investigate the cytotoxicity of NDNB-SMEDDS and the blank carrier. As shown in Figure 4, the blank SMEDDS did not show significant cytotoxicity in the dosage range of 1 to $40 \mu \mathrm{g} \cdot \mathrm{mL}^{-1}$, while a slight inhibition effect on cell proliferation was observed at the concentration of the blank carrier higher than $80 \mu \mathrm{g} \cdot \mathrm{mL}^{-1}$. This result is in good agreement with other published results. ${ }^{31}$ Because of the high concentration of surfactants used in SMEDDS, in vitro cell toxicity has been reported in many published studies. However, there are some differences between in vitro cell studies and in vivo conditions. For instance, the physiological sink conditions could dilute the dosage concentration, while the intestinal epithelium might 

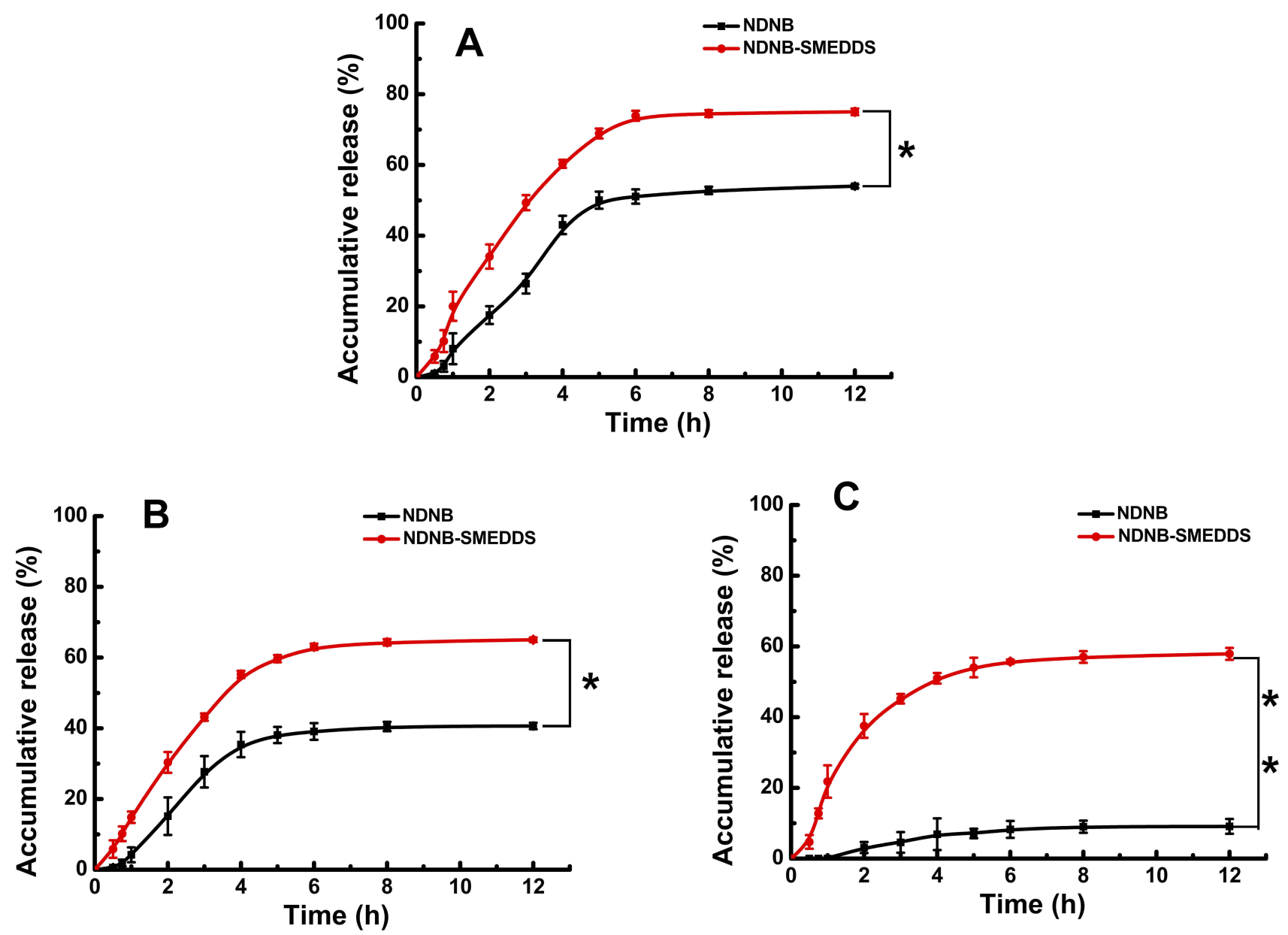

Figure 3 Dissolution curves of nintedanib and NDNB-SMEDDS soft capsule group in different dissolution media ((A): water, (B): pH6.8 PBS comprising 0.5\% Tween 80 , and (C): $\mathrm{PH7.4}$ PBS containing $0.5 \%$ Tween 80$), * \mathrm{P}<0.05$ and $* * \mathrm{P}<0.01$ compared nintedanib solution with NDNB-SMEDDS.

be protected by the mucus layers. ${ }^{32}$ Besides, the incubation time in the present study was long ( $24 \mathrm{hrs}$ ), which was much longer than the potential residence time of the drug in the intestinal tract. It could be speculated that the carriers may have very little influence on the gastrointestinal membrane. Indeed, SMEDDS loaded with nintedanib showed a little higher cytotoxicity than the blank SMEDDS. However, the cell viability was over $90 \%$ in the range of $1-40 \mu \mathrm{g} \cdot \mathrm{mL}^{-1}$, which suggested a low toxicity of the formulation and the potential to be used in the clinical setting.

\section{Transport Of NDNB-SMEDDS Through The Caco-2 Cell Monolayer}

The Caco-2 cell permeability method is widely used in screening the transport efficiency of new formulations. ${ }^{33}$ The transport of the nintedanib solution and NDNBSMEDDS were performed in both side directions and the results are shown in Table 5. The apparent permeability coefficients ( $P_{\text {app }} A$ to $B$ ) of NDNB-SMEDDS were $0.927 \times 10^{-6}$ and $2.563 \times 10^{-6} \mathrm{~cm} \cdot \mathrm{s}^{-1}$, respectively. Generally, substances with $P_{\text {app }}>1 \times 10^{-5} \mathrm{~cm} \cdot \mathrm{s}^{-1}$ are classified as having high permeability. Medium permeability substances possess $P_{\text {app }}$ values between $1 \times 10^{-5}$ and $1 \times 10^{-6} \mathrm{~cm} \cdot \mathrm{s}^{-1}$, while substances with $P_{\text {app }}<1 \times 10^{-6} \mathrm{~cm} \cdot \mathrm{s}^{-1}$ belong to low permeability substances. ${ }^{34}$ The calculated $P_{\text {app }}(A$ to $B$ ) of the solution was between $1 \times 10^{-5}$ and $1 \times 10^{-6} \mathrm{~cm} \cdot \mathrm{s}^{-1}$, which belongs to the medium permeability substance category. According to the classification, nintedanib belongs to low permeability substances, while the $P_{\text {app }}$ ( $A$ to $B$ ) of NDNB-SMEDDS increased by 2.8-fold compared with that of the solution, which could be classified as medium permeability. It was indicated that SMEDDS could significantly increase the permeability efficiency of nintedanib. Additionally, the permeated amounts of nintedanib across the cell monolayers from basolateral to apical directions ( $B$ to $A$ ) were lower than that from apical to basolateral directions ( $A$ to $B$ ), while the efflux ratio was less than 1 for both drug solution and SMEDDS. 


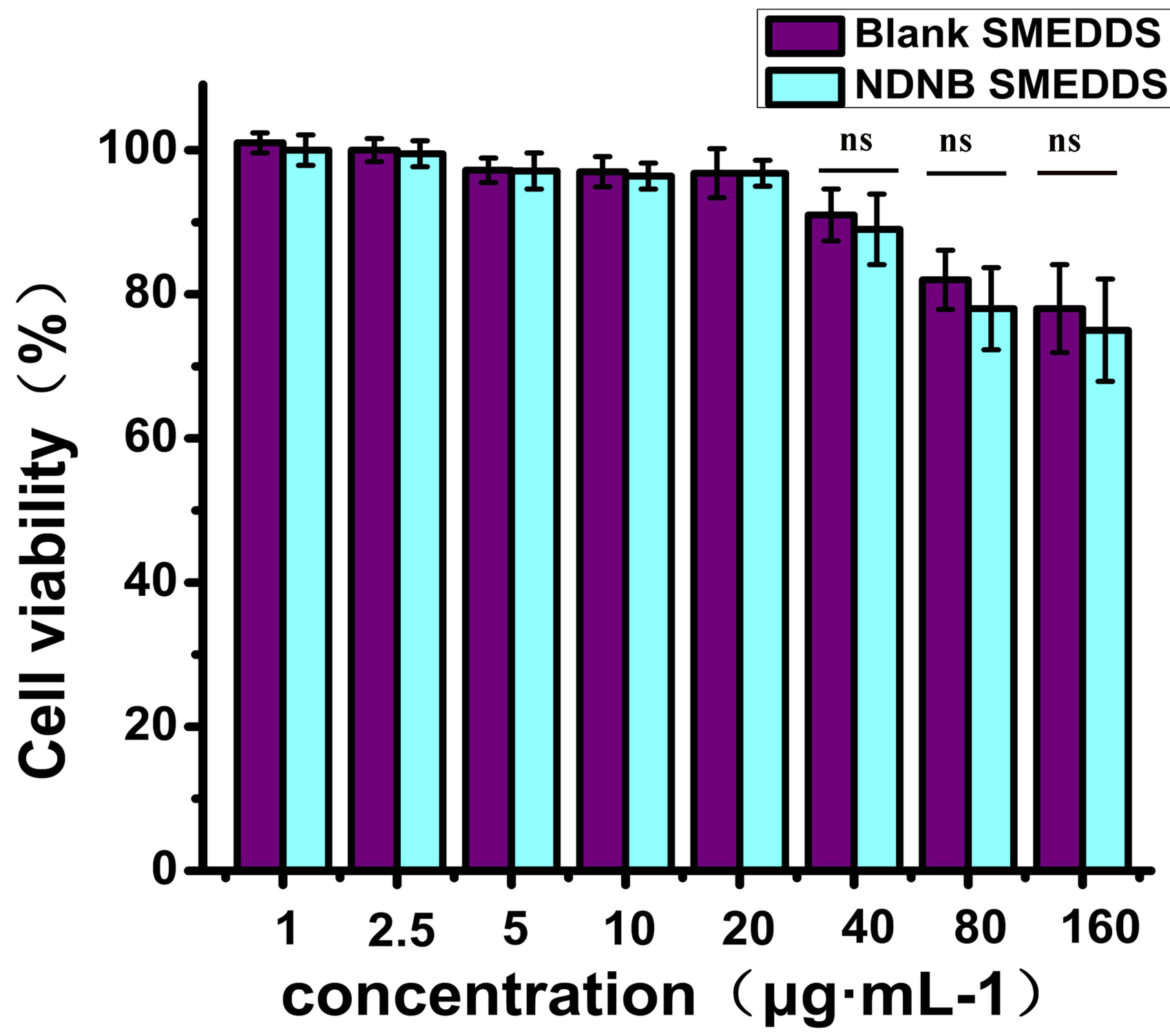

Figure 4 Evaluation of toxicity of SMEDDS on Caco-2 cells (mean $\pm S D, n=3$ ), ns=not significant.

These findings imply that no efflux transporter was involved in the drug permeability process across the Caco-2 cell monolayers, as the efflux ratio was less than $2 .{ }^{35}$ Yong-Mei Yin et al revealed that the $B$ to $A P_{\text {app }}$ was higher than that of the $A$ to $B$ value, indicating that docetaxel is a substrate of

Table 5 Transport Of NDNB-SMEDDS Through The Caco-2 Cell Monolayer $(\mathrm{X} \pm \mathrm{SD}, \mathrm{N}=3)$

\begin{tabular}{|l|l|l|l|}
\hline \multirow{2}{*}{ Rx } & \multicolumn{2}{|l|}{$\begin{array}{l}\text { Permeability Coefficient } \\
\text { E }\end{array}$} & \multirow{2}{*}{ Efflux Ratio } \\
\cline { 2 - 3 } & A to $\mathbf{B}$ & $\left.\mathbf{B} \mathbf{0}^{-6} \mathrm{~cm} \cdot \mathbf{s}^{-1}\right)$ & \\
\hline Nintedanib solution & $0.927 \pm 0.018$ & $0.783 \pm 0.021$ & $0.845 \pm 0.031$ \\
NDNB-SMEDDS & $2.563 \pm 0.104$ & $1.753 \pm 0.088$ & $0.684 \pm 0.023$ \\
\hline
\end{tabular}

P-gp. ${ }^{36}$ However, nintedanib exhibited higher $A$ to $B P_{\text {app }}$ than $B$ to $A P_{\text {app, }}$, suggesting nintedanib might not be a substrate of P-gp. Overall, the SMEDDS formulation could decrease the efflux ratio of the drug. Therefore, in addition to the effect of increasing drug solubility, the SMEDDS formulation had the ability to improve $A$ to $B$ permeability of nintedanib.

\section{Intestinal Circulation Study}

The apparent first-order absorption rate coefficients $\left(K_{a}, \mathrm{~h}^{-1}\right)$ and apparent permeability values $\left(P_{\text {app }}, 10^{-4} \mathrm{~cm} \cdot \mathrm{s}^{-1}\right)$ of nintedanib and SMEDDS loaded nintedanib are indicated in Table 6. Notably, an $R$ value of $K_{a}$ was $>0.9$, indicating that the absorption of nintedanib or nintedanib from SMEDDS 


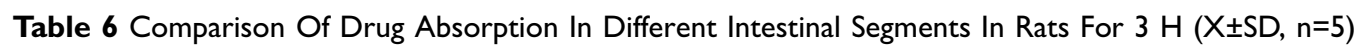

\begin{tabular}{|c|c|c|c|c|c|c|}
\hline Absorption Site & Samples & $K_{a}\left(h^{-1}\right)$ & $R$ value & $P_{\text {app }}\left(* 10^{-6} \mathrm{~cm} \mathrm{~s}^{-1}\right)$ & $F_{\mathrm{abs}}(\%)$ & $P_{\text {app }}$ Caco-2 $\left(* 10^{-6} \mathrm{~cm} \mathrm{~s}^{-1}\right)$ \\
\hline \multirow[t]{2}{*}{ Duodenum } & NDNB solution & $0.050 \pm 0.011$ & 0.925 & $1.132 \pm 0.249$ & $13.929 \pm 3.246$ & \\
\hline & NDNB-SMEDDS & $0.141 \pm 0.016^{* *}$ & $0.987^{* *}$ & $3.192 \pm 0.362 * *$ & $34.492 \pm 4.687$ & \\
\hline \multirow[t]{2}{*}{ Jejunum } & NDNB solution & $0.050 \pm 0.019$ & 0.939 & $1.132 \pm 0.430$ & $13.929 \pm 5.54$ & \\
\hline & NDNB-SMEDDS & $0.149 \pm 0.022 * *$ & $0.991 * *$ & $3.373 \pm 0.498 * *$ & $36.045 \pm 6.387$ & \\
\hline \multirow[t]{2}{*}{ Ileum } & NDNB solution & $0.045 \pm 0.009$ & 0.922 & $1.019 \pm 0.204$ & $12.628 \pm 2.664$ & \\
\hline & NDNB-SMEDDS & $0.130 \pm 0.014^{* *}$ & $0.970^{*}$ & $2.943 \pm 3.167 * *$ & $32.294 \pm 4.113$ & \\
\hline \multirow[t]{2}{*}{ Entire small intestine } & NDNB solution & $0.049 \pm 0.013$ & 0.964 & $1.109 \pm 2.943$ & $13.670 \pm 3.825$ & \\
\hline & NDNB-SMEDDS & $0.145 \pm 0.030$ & 0.943 & $3.283 \pm 6.792$ & $35.273 \pm 8.607$ & \\
\hline \multirow[t]{2}{*}{ Colon } & NDNB solution & $0.037 \pm 0.007$ & 0.919 & $1.911 \pm 1.585$ & $10.506 \pm 2.078$ & 0.927 \\
\hline & NDNB-SMEDDS & $0.120 \pm 0.013^{* *}$ & $0.956 *$ & $6.197 \pm 0.294 * *$ & $30.232 \pm 3.825$ & 2.563 \\
\hline
\end{tabular}

Notes: $* \mathrm{P}<0.05, * * \mathrm{P}<0.01$, compared NDNB solution with NDNB-SMEDDS.

was a first-order kinetic process in the rat intestinal and colon. Likewise, the nintedanib solution showed similar permeability $\left(P_{\text {app }}\right)$ in different small intestinal segments with no significant difference within the groups (duodenum, jejunum and ileum). Also, the $P_{\text {app }}$ in the colon was higher than that in the small intestine, amidst the same situations being observed in NDNB-SMEDDS. These results demonstrated that nintedanib could be absorbed in the whole intestine. In addition, the $P_{\text {app }}$ of NDNB-SMEDDS in each intestinal segment was significantly higher than that of the nintedanib solution $(\mathrm{P}<0.01)$. The $P_{\text {app }}$ of NDNB-SMEDDS increased by 3.0fold in the entire intestine and 3.2-fold in the colon compared to the drug solution, respectively. According to Figure 5A-D, the cumulative absorption of the nintedanib solution and NDNB-SMEDDS increased with time in each of the intestine segments. The $F_{\text {abs }}$ of NDNB-SMEDDS increased by 2.6and 2.9-fold compared with that of the solution in the small intestine and colon, respectively. These data indicated that the self-microemulsion preparation could effectively increase the absorption rate and extent of nintedanib in various bowel segments, which was beneficial to improving the oral absorption of the drug.

There are two commonly used perfusion methods to evaluate the drug permeability in vivo, namely the single pass intestinal perfusion (SPIP) model and the closedloop Doluisio method. In the SPIP approach, each drug molecule only has one chance to pass through the intestine, whereas in the Doluisio method the drug solution remains within the investigated intestinal segment during the entire experiment, ${ }^{27}$ indicating that only a small volume of drug solution is required. Moreover, the initial non-equilibrium phase of the drug transport could reflect in the Doluisio method. In this study, the Doluisio method was chosen to evaluate the permeability of the nintedanib solution and NDNB-SMEDDS in the small intestine and colon. It is generally agreed that the small intestine is the main site of absorption, with the colon being less important than the former. However, the available literature supports the colon as having high permeability for some drugs. ${ }^{37,38}$ In this study, we investigated the permeability of nintedanib in free form and in SMEDDS loaded form using different intestinal segments and the colon. Both dosage forms (nintedanib solution and NDNB-SMEDDS) showed higher permeability $\left(P_{\text {app }}\right)$ in the colon versus small intestine, which were not dependent on $\mathrm{pH}$ differences in the intestine and colon amidst the utilization of the same perfusion solution for both segments. This result is in accordance with the existing literature on low permeability basic drugs. ${ }^{39}$ Besides, we observed that rat colon permeability values $\left(P_{\text {app }}\right)$ obtained by the Doluisio method (1.911 $\pm 1.585 \times 10-6 \mathrm{~cm} \cdot \mathrm{s}^{-1}$ for nintedanib solution and 6.197 $\pm 0.294 \times 10^{-6} \mathrm{~cm} \cdot \mathrm{s}^{-1}$ for NDNB-SMEDDS) were higher than that obtained for the human colon using the Caco2 model $\left(0.927 \pm 1.585 \times 10^{-6} \mathrm{~cm} \cdot \mathrm{s}^{-1}\right.$ for nintedanib and $2.536 \pm 0.294 \times 10^{-6} \mathrm{~cm} \cdot \mathrm{s}^{-1}$ for NDNB-SMEDDS). This may be attributed to the tight difference of the paracellular pathway between rats and human. Finally, the SMEDDS could significantly increase the permeability $\left(P_{\text {app }}\right)$ and Fabs of nintedanib in both the small intestine and colon. It is indicated that SMEDDS technology can beneficially enhance the absorption of nintedanib in the whole intestine, not only because of the increase in solubility of drugs but also for the permeability improvement. 

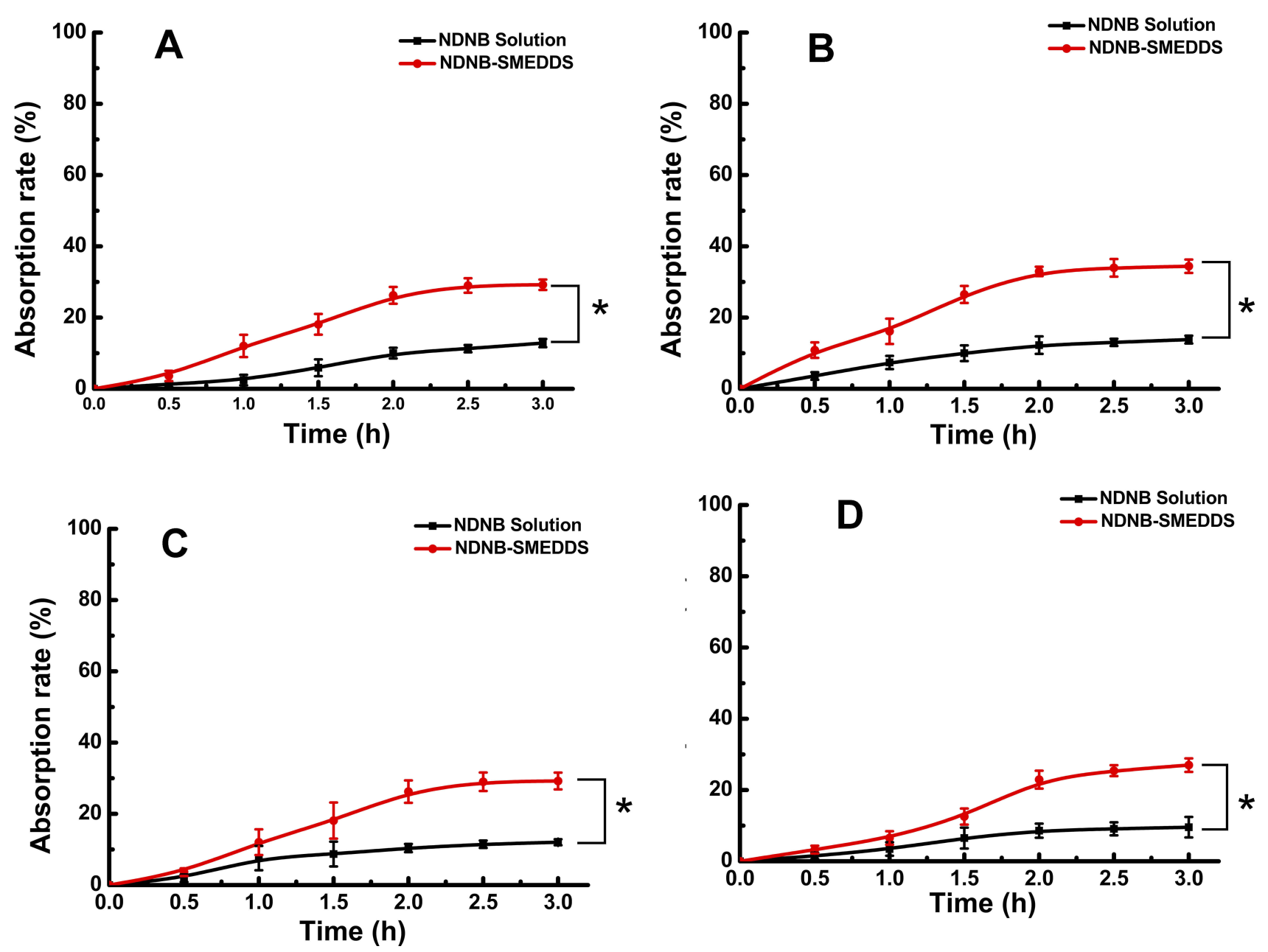

Figure 5 The cumulative absorption rate of nintedanib from solution and SMEDDS at $20 \mu \mathrm{g} \cdot \mathrm{mL}^{-1}$ at different intestinal segments. ((A): duodenum, (B): jejunum, (C): ileum, (D): colon. Results were expressed in mean $\pm S D, n=5)$, ${ }^{*}<0.05$, compared nintedanib solution with NDNB-SMEDDS.

\section{In vivo Pharmacokinetics}

The mean plasma concentration-time profiles of nintedanib and the pharmacokinetic parameters are shown in Figure 6 and Table 7. The plasma concentration of the NDNBSMEDDS was significantly higher than the nintedanib soft capsule almost at each time point. The $C_{\max }$ of the nintedanib soft capsule was $2.651 \pm 0.290 \mu \mathrm{g} \cdot \mathrm{mL}^{-1}$, while that of the NDNB-SMEDDS increased by 2.3-fold $(6.084 \pm 0.591$ $\mu \mathrm{g} \cdot \mathrm{mL}^{-1}$ ) compared with nintedanib soft capsule. The AUC was substantially enhanced by 2.5 -fold in the NDNBSMEDDS group compared with the nintedanib soft capsule group $\left(30.473 \mu \mathrm{g} \cdot \mathrm{h} \cdot \mathrm{mL}^{-1}\right.$ of NDNB-SMEDDS vs 12.706 $\mu \mathrm{g} \cdot \mathrm{h} \cdot \mathrm{mL}^{-1}$ of nintedanib soft capsule, $\left.\mathrm{P}<0.01\right)$. This result is consistent with that of the closed-loop Doluisio method, wherein the Fabs of the NDNB-SMEDDS-treated group increased by 2.6 times in intestinal circulation. These results

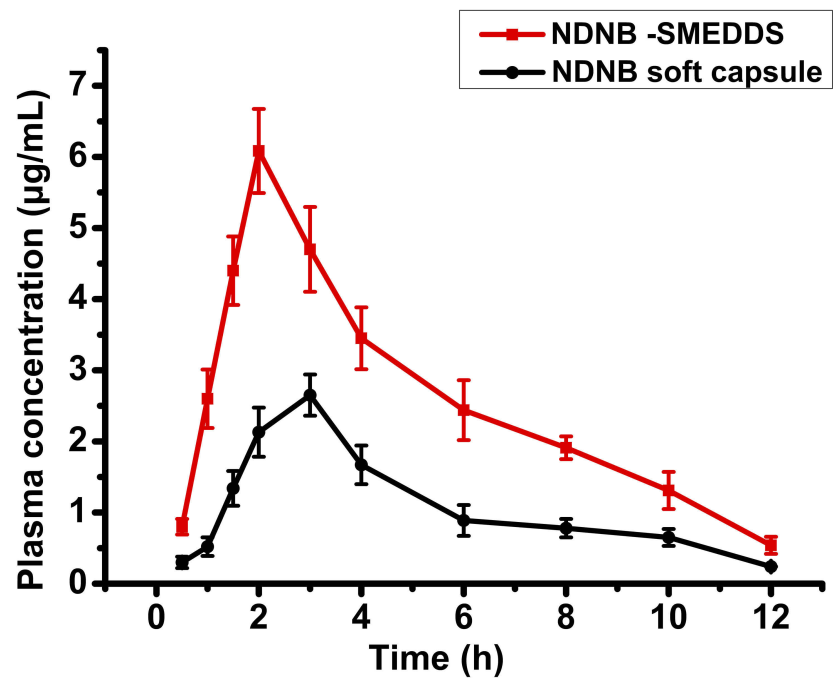

Figure 6 Drug concentration-time curves of nintedanib soft capsule and NDNBSMEDDS (mean $\pm S D, n=5)$. 
Table 7 Pharmacokinetic Parameters Of Nintedanib Soft Capsule And NDNB-SMEDDS $(X \pm S D, n=5), \quad * * P<0.01$, Compared Nintedanib Soft Capsule With NDNB-SMEDDS

\begin{tabular}{|l|l|l|}
\hline Parameter & NDNB Soft Capsule & NNDB-SMEDDS \\
\hline $\mathrm{t}_{\mathrm{I} / 2}(\mathrm{~h})$ & $4.039 \pm 0.7 \mathrm{I}$ & $4.235 \pm 0.605$ \\
$\mathrm{MRT}_{0-12}(\mathrm{~h})$ & $4.795 \pm 0.897$ & $4.713 \pm 0.560$ \\
$\mathrm{AUC}_{0-\mathrm{t}}\left(\mu \mathrm{g} \cdot \mathrm{h} \cdot \mathrm{mL}^{-1}\right)$ & $12.706 \pm 2.493$ & $30.473 \pm 3.088^{* *}$ \\
$C_{\max }\left(\mu \mathrm{g} \cdot \mathrm{mL}^{-1}\right)$ & $2.6505 \pm 0.498$ & $6.084 \pm 0.814^{* *}$ \\
$T_{\max }(\mathrm{h})$ & 3 & 2 \\
$K\left(\mathrm{~h}^{-1}\right)$ & $0.177 \pm 0.031$ & $0.167 \pm 0.024$ \\
$C I / F\left(\mathrm{~L} \cdot \mathrm{h}^{-1} \cdot \mathrm{kg}^{-1}\right)$ & $0.572 \pm 0.027$ & $0.258 \pm 0.016$ \\
$V / F\left(\mathrm{~L} \cdot \mathrm{kg}^{-1}\right)$ & $3.087 \pm 0.0 .062$ & $1.275 \pm 0.03 \mathrm{I}^{* *}$ \\
\hline
\end{tabular}

indicate that NDNB-SMEDDS could improve the absorption of the drug in vivo by potentially enhancing the permeability of the drug in the intestine. Furthermore, $T_{\max }$ of NDNBSMEDDS was prolonged for extra $1 \mathrm{hr}$ compared with nintedanib soft capsule ( $2 \mathrm{hrs}$ vs $3 \mathrm{hrs}$ ), indicating that SMEDDS could keep the drug in circulation to enhance the absorption rate in vivo.

Pharmacokinetic results indicated that the SMEDDS could improve the absorption and ameliorate the bioavailability of nintedanib, which agrees with the results of the intestinal circulation study and Caco-2 cell model. The mechanisms underlying the aforementioned phenomenon could be explained by the following effects. Firstly, the solubility of nintedanib in physical conditions could be increased by the SMEDDS approach. Secondly, the synergistic effect of surfactants and co-surfactants as absorption enhancers may be responsible for the superior permeability of the SMEDDS. ${ }^{40}$

\section{Conclusion}

In the present study, a self-microemulsion drug delivery system composed of MCT (oil phase), Cremophor RH 40 (surfactant) and ethylene glycol (co-surfactant) for the oral administration of nintedanib was developed. The characteristics of NDNB-SMEDDS, such as morphology, droplet size, stability and in vitro release were determined. The solubility of nintedanib was as low as $5.13 \mu \mathrm{g} \cdot \mathrm{mL}^{-1}$ in pH7.4 PBS, which could be significantly increased by using SMEDDS. Additionally, the in vitro transport study across the Caco- 2 cell model indicated that nintedanib belongs to low permeability substances, while SMEDDS technology could obviously increase the permeability of nintedanib. The results of the in vivo intestinal perfusion experiment are consistent with the Caco-2 cell, while the $P_{\text {app }}$ of NDNB-SMEDDS increased by 3.0 -fold in the entire intestine compared with the drug solution. Besides, the absorption of nintedanib in the whole intestine and colon was enhanced by SMEDDS. Thus, the AUC of NDNB-SMEDDS increased by 2.5 -fold compared with the soft capsule, which proved the SMEDDS approach could efficiently improve the oral bioavailability of nintedanib. Therefore, SMEDDS can act as a promising formulation for the better oral delivery of nintedanib.

\section{Acknowledgment}

This research was supported by the China Postdoctoral Science Foundation (2017M610309, 2019T120403), the Research Foundation for Advanced Scholars of Jiangsu University (No.11JDG122) and the Training Program for the Young Scholar of Jiangsu University.

\section{Disclosure}

The authors declare no conflicts of interest in this work.

\section{References}

1. Ley B, Collard HR, King TE Jr. Clinical course and prediction of survival in idiopathic pulmonary fibrosis. Am J Respir Crit Care Med. 2011;183(4):431-440. doi:10.1164/rccm.201006-0894CI

2. Martinez FJ, Safrin S, Weycker D, et al. The clinical course of patients with idiopathic pulmonary fibrosis. Ann Intern Med. 2005;142:963-967. doi:10.7326/0003-4819-142-12 Part 1-200506210-00005

3. Hilberg F, Tontsch-Grunt U, Baum A, et al. Triple angiokinase inhibitor nintedanib directly inhibits tumor cell growth and induces tumor shrinkage via blocking oncogenic receptor tyrosine kinases. J Pharmacol Exp Ther. 2018;364:494-503. doi:10.1124/jpet.117.244129

4. Hilberg F, Roth GJ, Krssak M, et al. BIBF 1120: triple angiokinase inhibitor with sustained receptor blockade and good antitumor efficacy. Cancer Res. 2008;68:4774 4782. doi:10.1158/0008-5472.CAN-07-6307

5. Porta R, Borea R, Coelho A, et al. FGFR a promising druggable target in cancer: molecularbiology and new drugs. Crit Rev Oncol Hematol. 2017;113:256-267. doi:10.1016/j.critrevonc.2017.02.018

6. Richeldi L, Du Bois RM, Raghu G, et al. Efficacy and safety of nintedanib in idiopathic pulmonary fibrosis. $N$ Engl J Med. 2014;370 (22):2071-2082. doi:10.1056/NEJMoa1402584

7. Okamoto I, Miyazaki M, Takeda M, et al. Tolerability of nintedanib (BIBF 1120) in combination with docetaxel: a phase 1 study in japanese patients with previously treated non-small-cell lung cancer. $J$ Thorac Oncol. 2015;10(2):346-352. doi:10.1097/JTO.0000000000000395

8. Eisen T, Shparyk Y, Jones R, et al. Phase II efficacy and safety study of nintedanib versus sunitinib in previously untreated renal cell carcinoma (RCC) patients. J Clin Oncol. 2013;31(15):4506. doi:10.1200/JCO.2013.49.0219

9. Capdevila J, Carrato A, Tabernero J, Grande E. What could Nintedanib (BIBF 1120), a triple inhibitor of VEGFR, PDGFR, and FGFR, add to the current treatment options for patients with metastatic colorectal cancer. Crit Rev Oncol Hematol. 2014;92(2):83-106. doi:10.1016/j.critrevonc.2014.05.004

10. McCormack PL. Nintedanib: first global approval. Drugs. 2015;75 (1):129-139. doi:10.1007/s40265-014-0335-0

11. Dallinger C, Trommeshauser D, Marzin K, Liesener A, Kaiser R, Stopfer P. Pharmacokinetic properties of nintedanib in healthy volunteers and patients with advanced cancer. J Clin Pharmacol. 2016;56 (11):1387-1394. doi:10.1002/jcph.752 
12. Wang H, Li Q, Deng W, et al. Self-nanoemulsifying drug delivery system of $\backslash \mathrm{r}$, trans $\backslash \mathrm{r}$, -cinnamic acid: formulation development and pharmacodynamic evaluation in alloxan-induced type 2 diabetic rat model. Drug Develop Res. 2015;76(2):82-93. doi:10.1002/ddr.21244

13. Omari-Siaw E, Zhu Y, Wang H, et al. Hypolipidemic potential of perillaldehyde-loaded self-nanoemulsifying delivery system in highfat diet induced hyperlipidemic mice: formulation, in vitro and in vivo evaluation. Eur J Pharm Sci. 2016;85:112-122. doi:10.1016/j. ejps.2016.02.003

14. Gu Z, Shi X, Omari-Siaw E, et al. Self-microemulsifying sustainedrelease pellet of Ginkgo biloba extract: preparation, in?vitro drug release and pharmacokinetics study in beagle dogs. J Drug Deliv Sci Tec. 2017;37:184-193. doi:10.1016/j.jddst.2017.01.002

15. Zhang Z, Huang J, Jiang S, et al. A high-drug-loading self-assembled nanoemulsion enhances the oral absorption of probucol in rats. $J$ Pharm Sci. 2013;102(4):1301-1306. doi:10.1002/jps.23460

16. Guo F, Zhong H, He J, et al. Self-microemulsifying drug delivery system for improved oral bioavailability of dipyridamole: preparation and evaluation. Arch Pharm Res. 2011;34(7):1113-1123. doi:10.10 07/s12272-011-0709-8

17. Lesheng T, Huan Y, Yingkun C, et al. Enhance bioavailability of nifidepine by self-emulsifying drug delivery system. J Investig Med. 2013;61(4):S14.

18. You X, Xing Q, Tuo J, et al. Optimizing surfactant content to improve oral bioavailability of ibuprofen in microemulsions: just enough or more than enough. Int J Pharm. 2014;471(1-2):276-284. doi:10.1016/j.ijpharm.2014.05.031

19. Haiyan L, Yonggang T, Lixia Y, et al. Dissolution evaluation in vitro and bioavailability in vivo of self-microemulsifying drug delivery systems for pH-sensitive drug loratadine. J Microencapsul. 2015;32:175-180. doi:10.3109/02652048.2014.985340

20. Valicherla GR, Valicherla GR, Syed AA, et al. Formulation optimization of Docetaxel loaded self-emulsifying drug delivery system to enhance bioavailability and anti-tumor activity. Sci Rep. 2016;6:1-11. doi:10.1038/srep26895

21. Kerns EH, Di L, Petusky S, Farris M, Ley R, Jupp P. Combined application of parallel artificial membrane permeability assay and Caco-2 permeability assays in drug discovery. $J$ Pharm Sci. 2004;93(6):1440-1453. doi:10.1002/jps.20075

22. Matsumoto T, Kaifuchi N, Mizuhara Y, Warabi E, Watanabe J. Use of a Caco-2 permeability assay to evaluate the effects of several Kampo medicines on the drug transporter P-glycoprotein. J Nat Med. 2018;72(4):897-904. doi:10.1007/s11418-018-1222-x

23. Liu H, Du K, Li D, et al. A high bioavailability and sustained-release nano-delivery system for nintedanib based on electrospray technology. Int J Nanomed. 2018;13:8379-8393. doi:10.2147/IJN

24. Moreno-Bautista G, Tam KC. Evaluation of dialysis membrane process for quantifying the in vitro drug-release from colloidal drug carriers. Colloids Surf A Physicochem Eng Asp. 2011;389(13):299-303. doi:10.1016/j.colsurfa.2011.07.032

25. Zorzan M, Collazuol D, Ribaudo G, et al. Biological effects and potential mechanisms of action of Pistacia lentiscus Chios mastic extract in Caco-2 cell model. J Funct Foods. 2019;54:92-97. doi:10.1016/j.jff.2019.01.007
26. Doluisio JT, Billups NF, Dittert LW, Sugita ET, Swintosky JV. Drug absorption: I. An in situ rat gut technique yielding realistic absorption rates. J Pharm Sci. 1969;58:1196-1200. doi:10.1002/jps.2600581006

27. Doluisio JT, Tan GH, Billups NF, et al. Drug absorption II: effect of fasting on intestinal drug absorption. J Pharm Sci. 1969;58 (10):1200-1202. doi:10.1002/jps.2600581007

28. Lozoya-Agullo I, Zur M, Fine-Shamir N. Investigating drug absorption from the colon: single-pass vs. Doluisio approaches to in-situ rat largeintestinal perfusion. Int $J$ Pharm. 2017;527:135-141. doi:10.1016/j. ijpharm.2017.05.018

29. Porter CJ, Pouton CW, Cuine JF, Charman WN. Enhancing intestinal drug solubilisation using lipid-based delivery systems. Adv Drug Deliver Rev. 2008;60(6):673-691. doi:10.1016/j.addr.2007.10.014

30. Man N, Wang QL, Li HH, et al. Improved oral bioavailability of myricitrin by liquid self-microemulsifying drug delivery systems. $J$ Drug Deliv Sci Tec. 2019;52:597-606. doi:10.1016/j.jddst.2019.05.003

31. Claudia M, Thomas H, Flavia L. In vivo evaluation of an oral selfemulsifying drug delivery system (SMEDDS) for exenatide. J Control Release. 2018;277:165-172. doi:10.1016/j.jconrel.2018.03.018

32. Menzel C, Bernkop-Schnürch A. Enzyme decorated drug carriers: targeted swords to cleave and overcome the mucus barrier. Adv Drug Deliv Rev. 2018;124:164-174. doi:10.1016/j.addr.2017.10.004

33. Evren G, Hatice YK, Cinel K. The novel oral imatinib microemulsions: physical properties, cytotoxicity activities and improved Caco-2 cell permeability. J Microencapsul. 2013;30(2):132-142. doi:10.3109/ 02652048.2012 .704952

34. Detroyer A, Stokbroekx S, Bohets H, et al. Fast monolithic micellar liquid chromatography: an alternative drug permeability assessing method for high-throughput screening. Anal Chem. 2004;76 (24):7304-7309. doi:10.1021/ac048944k

35. Wang X, Meng M, Gao L, Liu T, Xu Q, Zeng S. Permeation of astilbin and taxifolin in Caco-2 cell and their effects on the P-gp. Int $J$ Pharm. 1969;58:1-8. doi:10.1016/j.ijpharm.2009.05.022

36. Yin YM, Cui FD, Mu CF, et al. Docetaxel microemulsion for enhanced oral bioavailability: preparation and in vitro and in vivo evaluation. $J$ Control Release. 2009;140:86-94. doi:10.1016/j.jconrel.2009.08.015

37. Masaoka Y, Tanaka Y, Kataoka M, Sakuma S, Yamashita S. Site of drug absorption after oral administration: assessment of membrane permeability and luminal concentration of drugs in each segment of gastrointestinal tract. Eur J Pharm Sci. 2006;29(3-4):240-250. doi:10.1016/j.ejps.2006.06.004

38. Sjogren E, Abrahamsson B, Augustijns P, et al. In vivo methods for drug absorption - comparative physiologies, model selection, correlations with in vitro methods (IVIVC), and applications for formulation/API/excipient characterization including food effects. Eur $J$ Pharm Sci. 2014;57:99-151. doi:10.1016/j.ejps.2014.02.010

39. Lozoya-Agullo I, González-álvarez I, González-álvarez M, et al. In situ perfusion model in rat colon for drug absorption studies: comparison with small intestine and Caco-2 cell model. J Pharm Sci. 2015;104(9):3136-3145. doi:10.1002/jps.24447

40. Jo K, Kim H, Khadka P, et al. Enhanced intestinal lymphatic absorption of saquinavir through supersaturated self-microemulsifying drug delivery systems. Asian J Pharm Sci. 2019. doi:10.1016/j.ajps.2018.11.009

International Journal of Nanomedicine

Dovepress

\section{Publish your work in this journal}

The International Journal of Nanomedicine is an international, peerreviewed journal focusing on the application of nanotechnology in diagnostics, therapeutics, and drug delivery systems throughout the biomedical field. This journal is indexed on PubMed Central, MedLine, CAS, SciSearch ${ }^{\mathbb{B}}$, Current Contents ${ }^{\mathbb{B}} /$ Clinical Medicine,

Journal Citation Reports/Science Edition, EMBase, Scopus and the Elsevier Bibliographic databases. The manuscript management system is completely online and includes a very quick and fair peer-review system, which is all easy to use. Visit http://www.dovepress.com/ testimonials.php to read real quotes from published authors.

Submit your manuscript here: https://www.dovepress.com/international-journal-of-nanomedicine-journal 